issn: $1808-799 \mathrm{X}$

ano 6 - número 7 - 2008

\title{
A IMPOSSIBILIDADE DA RESSIGNIFICAÇÃO DAS COMPETÊNCIAS NUMA PERSPECTIVA MARXISTA
}

\author{
RODRIGUES, Daniel' - danielrodrigues7@yahoo.com.br
}

O presente trabalho tem como objetivo confrontar a propositura de formação da força de trabalho sob a lógica do modelo das competências com a perspectiva materialista históricodialética. Educadores, teóricos historicamente comprometidos com a causa emancipatória da classe trabalhadora vêm, com afinco, elaborando a crítica ao modelo dominante de competências e propondo uma ressignificação sob a matriz crítico-emancipatória. No nosso entendimento, esse esforço, mesmo caracterizado como um esforço sério e honesto na disputa pelo termo 'competência', é uma tarefa fadada a ser inviabilizada pela própria realidade.

Mesmo acertando no diagnóstico do modelo das competências, a tentativa de Deluiz, exatamente pelo seu compromisso, de dar uma saída favorável aos trabalhadores, no nosso entendimento, obscurece algumas questões centrais para o entendimento das competências. As exigências postas pelo padrão capitalista atual de acumulação flexível, neotayloista ou toyotista, que a própria autora aponta são: competitividade, produtividade, agilidade e racionalização de custos. A questão é: como ressignificar em favor dos trabalhadores essas exigências centrais intimamente ligadas ao modo de produção vigente?

No modelo das competências o controle da força de trabalho se expressa através de estratégias de ressocialização e aculturação pela conformação da subjetividade do trabalhador. A ênfase na identificação dos interesses de patrões e empregados - que se convertem em uma comunidade social de colaboradores -; a autogestão pela internalização da disciplina; o controle exercido sobre os trabalhadores por seus próprios colegas no trabalho em equipe e a sobrevalorização de aspectos atitudinais (o saber-ser) conferem ao modelo das competências a possibilidade de um controle menos formalizado e mais difuso sobre a força de trabalho, evitando-se as resistências e os conflitos (Deluiz, 2001, p.2).

\footnotetext{
${ }^{1}$ Professor Adjunto do Departamento de Fundamentos Sócio-Filosóficos da Educação - Centro de Educação - Universidade Federal de Pernambuco.
} 
issn: $1808-799 \mathrm{X}$

ano 6 - número 7 - 2008

Como vemos, o modelo das competências revela-se como um processo de controle mais intenso com um formato mais sutil. Este processo é exposto através de um movimento de construção de uma nova internalização, que é exatamente a expressão mais acabada dos interesses capitalistas, a nosso ver impondo aos trabalhadores um novo 'ser', e este deve desenvolver a sua suposta identidade enquanto um capitalista. É um comportamento inicialmente requerido e desenvolvido para os executivos e posteriormente ampliado para o conjunto dos trabalhadores. Sem estas características, desenvolvidas neste novo tipo de controle, não teria sentido o modelo das competências diagnosticado por Deluiz.

Esse modelo está umbilicalmente ligado a uma expressão fetichizada da mercadoria. No caso, à mercadoria força de trabalho. A defesa da prática e da teoria do modelo das competências, tem como pressuposto o caráter ahistórico da força de trabalho. Retira-se o movimento que compôs o proletariado como classe fundamental na reprodução do capitalismo: o processo de extração do trabalho excedente, obscurecendo a transformação em mercadoria da força de trabalho e seu lugar subalterno nessa relação de compra e venda. Nesse processo atual, de construção da força de trabalho, é fundamental a manutenção da exploração, da divisão da classe trabalhadora, da concorrência e da absorção dos fundamentos capitalistas pela mesma.

Já Acácia Kuenzer (2004, p.1) define a competência de outra forma.

Naquela ocasião, com apoio na teoria, mas também nas entrevistas levadas a efeito com 148 operadores, mostramos que é possível compreender a categoria competência como a capacidade de agir, em situações previstas e não previstas, com rapidez e eficiência, articulando conhecimentos tácitos e científicos a experiências de vida e laborais vivenciadas ao longo das histórias de vida.[...] vinculada à idéia de solucionar problemas, mobilizando conhecimentos de forma transdisciplinar a comportamentos e habilidades psicofísicas, e transferindo-os para novas situações; supõe, portanto, a capacidade de atuar mobilizando conhecimentos.

No nosso entendimento, a autora não aponta para uma leitura da realidade como um todo, resumindo-a em um aspecto da mesma, inclusive no seu aspecto metodológico da construção do conceito, ou mais precisamente, da noção de competências. O problema está na ênfase colocada, como se a realidade do trabalho fosse apenas um operativo técnico, como se estivesse em jogo somente a perspectiva de um desenvolvimento do trabalho enquanto parte das forças produtivas. Não se apresenta as competências, para a autora, como parte das relações sociais existentes de produção capitalista na atualidade. Nesta definição, Kuenzer vai se restringir a uma visão por dentro da fábricaii, colocando a ação próxima do conceito de 
issn: $1808-799 \mathrm{X}$

ano 6 - número 7 - 2008

eventos, da imprevisibilidade, como a mobilização de todos os seus conhecimentos para resolver algum problema. Ela vai descrever toda a capacidade de trabalho para o processo produtivo, sem articular que este processo de trabalho é o movimento fundamental de extração da mais-valia do trabalho não-pago. Além desta visão, a autora superpõe o conceito de praxis, bem colocado por Vázquez, dando a entender que o mesmo se aproximaria da categoria das competências em sua ressignificação.

Ao assim compreender a categoria competência, já se conferia destaque ao ponto que constitui objeto deste texto: a necessidade de desenvolver a capacidade de articular conhecimentos teóricos e práticas laborais, reafirmando-se a compreensão de que o simples domínio do conhecimento por parte do operador, seja tácito, seja científico, não é suficiente para que se estabeleça a competência, compreendida na sua dimensão de práxis, posto que esta, segundo Vázquez, 'é atividade teórica e prática que transforma a natureza e a sociedade; prática, na medida em que a teoria, como guia da ação, orienta a atividade humana; teórica, na medida em que esta ação é consciente' (Kuenzer, 2004, p.1-2).

Além disto, a autora olvida as caracterizações críticas da competência, como por exemplo, as já citadas por Deluiz. A divisão social do trabalho não aparece nesta concepção, nem a perspectiva da subsunção real, muito menos a visão da mercantilização da força de trabalho, apesar de ter a mesma como referência a praxis revolucionária e sabendo estar dentro "[d]o regime da acumulação flexível" (Kuenzer, 2004, p.3).

O nosso esforço de apresentar a competência partindo dos fundamentos capitalistas tem como objetivo demonstrar que esse conceito existente carrega consigo uma prática histórica de divisão social do trabalho, a perspectiva não só sob o ângulo de uma força produtiva, mas também inserida nas relações sociais capitalistas vigentes e hegemônicas. A divisão capitalista do trabalho caracteriza claramente a serventia essencial do modelo de competências, de forma mais radical, a exigir uma inserção maior dos trabalhadores na visão e prática do capital hodierno. Em sua essência, o modelo não deixa dúvidas de que deve, no mínimo, respeitar e, na média, defender os interesses das empresas, ou melhor, dos empresários - em sua particularidade, o que significa uma defesa da reprodução do modo societal de organização. Os projetos de formação exigem, nessa lógica, a aplicação dos objetivos que o capital impõe coercitivamente ou por consenso à força de trabalho.

Kuenzer aborda a situação contraditória em que o trabalhador, na acumulação do capital, estaria a favor da exploração de sua força de trabalho, mas não daria uma conseqüência a esta assertiva. Critica o pragmatismo, mas não identifica a própria competência 
issn: $1808-799 \mathrm{X}$

\section{ano 6 - número 7 - 2008}

como parte intrínseca de teorias defensoras do sistema capitalista, como o pragmatismo, a postura eclética, a pós-modernidade. Questiona as competências sob cunho neoliberal, que dão ênfase aos comportamentos e não efetivamente aos conhecimentos transversais. Ressalta a relação entre o sujeito e objeto, mas abdica da possibilidade da prática revolucionária. Este movimento é muito comum, quando se faz a crítica terminal do taylorismo/fordismo, tomando-a enquanto a própria crítica ao capital como um todo. O formato taylorista de produzir é vertido como se fora o único e absoluto. Com sua decadência hegemônica, na aparência, oferece uma profunda modificação nas relações sociais de produção como um todo. A expressão histórica dentro do capitalismo torna-se a própria relação capitalista. Conseqüentemente, a percepção das competências se apresenta como uma grande saída dessa relação mecânica, injusta, hierárquica, entre outras características. As vantagens, nessa concepção, são encontradas na produção flexível e, portanto, é passível de se dar um salto de qualidade positivo em direção aos interesses de uma empresa e dos trabalhadores concomitantemente, na atualidade ${ }^{i i i}$. Um modelo de competências capitalista em essência torna-se 'libertário'. A autora cita o seu estudo na Repar (Refinaria Getúlio Vargas):

A concepção metodológica que vem sendo desenvolvida na Repar, e que na prática já vem se evidenciando adequada, compreende o processo de produção do conhecimento como resultante da relação entre o homem e as relações sociais em seu conjunto, através da atividade humana (Kuenzer, 2004, p.15).

Deluiz também faz referência ao lado positivo do modelo das competências, único argumento importante, a nosso ver, para construir a teoria da ressignificação do mesmo. No nosso entendimento, compõe a própria objetivação do processo do trabalho a apropriação da forma existente da produção. Seria impossível o trabalhador sobreviver sem estar dentro dessa totalidade e, é claro, o próprio capitalista busca esse mesmo objetivo, pois ambos estão inseridos neste condicionamento histórico. Ocorre, então, um movimento de apropriação, por parte dos trabalhadores, dos processos de desenvolvimento das forças produtivas. Os trabalhadores compõem parte fundamental da criação desses processos, mesmo dentro de um movimento alienante. Se isolássemos alguns elementos que compõem a noção de competências, colocando-os fora do contexto capitalista atual, não haveria um ser humano que contestasse esses ingredientes, como a autonomia ou a criatividade, por exemplo.

Compreendemos que estas características das competências devem ser analisadas dentro do objeto maior e das relações de que advém, no caso, das competências dentro das relações capitalistas. Ali, o significado é decodificado pelos interesses do capital. Até podem 
issn: $1808-799 \mathrm{X}$

ano 6 - número 7 - 2008

existir disputas de elementos isolados, como a autonomia, mas vistas dentro de uma relação coisificada, mercantilizada, ela passa a ter um significado, pois é uma prática classista burguesa. Essa é a totalidade em que se apresentam as competências, com uma natureza e objetivo histórico da radicalização da formação da força de trabalho enquanto mercadoria, ou seja, a sua coisificação potencializada.

Em "Miséria da Filosofia", Marx, em contraposição à Proudhon, apontava que a dialética da vida, conseqüentemente da compreensão da realidade não poderia ser algo arbitrário ou ainda elemento de superação no sentido da separação do próprio objeto. Critica Proudhon, apontando a lógica de separar as coisas boas das más, aproveitando-se das boas, com vistas a uma superação dialética. Ironicamente Marx (1985, p.90) comenta:

La esclavitud uma categoria económica como otra cualquiera. Por consiguiente, también tiene sus dos lados. Dejemos el lado malo de la esclavitud y hablemos de su lado bueno; de suyo se comprende que sólo se trata de la esclavitud directa, de la esclavitud de los negros en Surinam, en le Brasil, en los estados meridionales de America del Norte.

Segue Marx adiante:

La coexistencia de dos lados contradictorios, su lucha y su fusión en una nueva categoría constituyen el movimiento dialéctico. El que se plantea el problema de eliminar el lado malo, con ello mismo pone fine de golpe al movimiento dialéctico Ya no es la categoría la que se sitúa en si misma y se opone a si misma en virtud de su naturaleza contradictoria, sino que es el señor Proudhon el que se mueve, forceja y se agita entre los dos lados de la categoría. (...)Toma al primera categoría que se le viene a mano y le atribuye arbitrariamente la propiedad de suprimir los inconvenientes de la categoría que se trata depurar. (Marx,1985, p.91)

A tentativa de 'salvar' a categoria competências retira a materialidade e a historicidade do movimento dialético. Mesmo fragmentado e reificado, entendemos que o trabalho é realizador da construção da humanidade. É a capacidade de trabalho posta em movimento em condições determinadas que realiza a objetivação do trabalho. No entanto, devemos ser bastante criteriosos nessa referência ao firmamos formalmente sobre o lado positivo do processo de trabalho, pois o mesmo, em hipótese alguma, deve ser visto desligado de sua referência histórica e, conseqüentemente, de suas conseqüências nefastas. Além disso, no processo de fetichização, esses elementos considerados positivos, quando tomados idealizadamente, adquirem um caráter contrário ao postulado pela burguesia. Marx já apontava a utilização das exigências ao trabalhador de apreender em sua formação as variadas exigências dos diversos ramos de trabalho, mas nunca desvinculando da sua natureza real 
issn: $1808-799 \mathrm{X}$

ano 6 - número 7 - 2008

dentro do capitalismo, com seus efeitos trágicos para ele:

Por meio da maquinaria, dos processos químicos e de outros modos, a indústria moderna transforma continuamente, com a base técnica da produção, as funções dos trabalhadores e as combinações sociais do processo de trabalho. Com isso revoluciona constantemente a divisão do trabalho dentro da sociedade e lança ininterruptamente massas de capital e massa de trabalhadores de um ramo de produção para outro. Exige, por sua natureza, variação do trabalho, isto é, fluidez das funções, mobilidade do trabalhador em todos os sentidos. Entretanto, reproduz em sua forma capitalista a velha divisão do trabalho com suas peculiaridades rígidas. Já vimos como essa contradição absoluta elimina toda a tranqüilidade, solidez e segurança da vida do trabalhador, mantendo-o sob a ameaça constante de perder os meios de subsistência ao ser-lhe tirado das mãos o instrumental do trabalho, de tornar-se supérfluo, ao ser impedido de exercer sua função parcial; com essa contradição se patenteia poderosa na hectacombe ininterrupta de trabalhadores, no desgaste sem freio das forças de trabalho e nas devastações da anarquia social. Este é o aspecto negativo (Marx, 1989, p. 557/8).

Ao mesmo tempo, Marx percebia que no movimento de desenvolvimento das forças produtivas, da maquinaria, em especial, eram exigidas novas habilidades dos trabalhadores. Era exigido um câmbio de um ramo para outro, uma "maior versatilidade possível do trabalhador" (MARX, 1989, p.558). Observava que, com a reprodução destes termos na divisão capitalista do trabalho, tinha como conseqüência a eliminação da tranqüilidade diante da perda do emprego, diante de uma instabilidade contratual. As novidades da fluidez, da mobilidade em geral dos trabalhadores, não perdia as peculiaridades determinadas do trabalho assalariado, explorado. Não são tão novas as conseqüências reais da formação da força de trabalho enquanto mercadoria e, mesmo dentro de sua positividade, a realização do trabalho humano carrega as relações de exploração: "Ele só opera dentro de uma conexão que só existe depois da venda, no interior da oficina capitalista" (MARX, 1989, p.413). Não há como existir e, portanto, pensar este modelo fora das relações de exploração. O que Marx aponta, nessas modificações existentes, são rupturas de maneiras de se produzir, que só subsistem dentro da necessária exploração capitalista. É um processo revolucionário dentro da lógica do funcionamento capitalista de produção. As positividades existentes devem ser entendidas e, portanto, mediadas dentro dos limites da própria relação capitalista, dentro da mercantilização da força de trabalho e de sua fetichização. Quando separamos o lado positivo do negativo, formalmente, passamos a não entender o sentido da relação de exploração existente dentro dessa totalidade, em especial e atualmente, o modelo das competências. Vejamos os limites do 'aspecto positivo' deste benefício.

A adoção do modelo das competências no mundo do trabalho traz, no entanto, 
issn: $1808-799 X$

ano 6 - número 7 - 2008

implicações contraditórias para o trabalhador. Por um lado, pode-se apontar, como aspecto positivo, a valorização do trabalho, que assume um caráter mais intelectualizado, menos prescritivo, exigindo a mobilização de competências que envolvem domínios cognitivos mais complexos e que vão além da dimensão técnica, demandando novas exigências de qualificação do trabalhador e a elevação dos níveis de escolaridade. Ressalta-se, também, positivamente, a valorização dos saberes em ação, da inteligência prática dos trabalhadores, independente de títulos ou diplomas; uma maior polivalência do trabalhador, que lhe permite lidar com diferentes processos e equipamentos, assumir diferentes funções e tornar-se multiqualificado; a possibilidade de construir competências coletivas a partir do trabalho em equipe, maior comunicação, participação e autonomia para o planejamento, execução e controle dos processos produtivos (DELUIZ, 2001, p.3 - Grifos nossos).

O primeiro ponto levantado por Deluiz é a valorização do trabalho. O sentido mais correto é que o capital não prescinde do trabalho. Ele é fundante na construção da riqueza, já dizia Smith. Portanto, o trabalho é a fonte de valor, diferentemente de sua valorização por parte da burguesia na própria relação capitalista de produção. Por outro lado, o sentido está na 'valorização' (com a precarização e tudo) específica de um trabalho relacionado com o intelectual, menos prescritivo, mais complexo, indo além da questão de conhecimentos teóricos. Ora, o lado mais intelectual exigido do trabalhador é a sua predisposição para aumentar a produtividade, respondendo às necessidades do capital. Ou seja, uma intelectualidade ainda mais submetida à lógica do executivo, do capitalista.

Utilizar a intelectualidade para questionar, para subverter a lógica do capital, é extremamente danoso e perigoso para o crescimento da empresa, do capital. Contrariamente ao modelo das competências, uma nova intelectualidade positiva organizacional seria, no nosso entendimento, relacionada com a possibilidade do trabalhador conhecer a ciência e também sua aplicabilidade em benefício da coletividade. Esta, no entanto, não nos parece ser a característica da utilização do saber como competência. Esta caracterização, pelo contrário, fica impedida ao trabalhador, ou, se quisermos 'individualizar', à maioria dos trabalhadores de sua realização, pois o critério do capital é a sua utilidade para realizar o produto enquanto uma mercadoria, para a extração e realização da mais-valia, com interesse especial sobre o lucro. Fica paradoxal entender este modelo como a base redentora dos trabalhadores oferecendo a desfragmentação de seu trabalho, portanto um encontro dentro do processo produtivo, vizualização esta, para nós, desligada das condições concretas impostas nas relações de exploração existentes.

Quanto à polivalência, esta já foi muito contestada por Frigotto (1996) e outros autores, 
issn: $1808-799 \mathrm{X}$

\section{ano 6 - número 7 - 2008}

como uma ação do capital no aproveitamento dos conhecimentos e das habilidades do trabalhador, incorporando-os ao processo produtivo. Ela está relacionada a um processo de intensificação do trabalho, com o aumento da produtividade, na finalidade de combater a tendência organizacional da diminuição das taxas de lucro.

Por fim, a individualização é uma expressão da fragmentação desenvolvida a partir das relações sociais produtivas, colocada para os trabalhadores. É uma necessidade do capital. O que dá o ponto da unidade, condensando os esforços humanos, é o próprio capital, os seus interesses que, obviamente, caminham contra os interesses reais e gerais dos trabalhadores. A maior participação, a autonomia, prática real (e ideologizada) do modelo das competências, é um movimento de controle do trabalho sob outra formatação.

De forma alguma esses movimentos são efetivamente autônomos contraditando os interesses do capital. Portanto, mesmo os dados levantados como positivos devem ser mediados a partir da seguinte questão: como o capital os utiliza e os constrói enquanto competências em seu benefício? Como se processa a autonomia, a participação, o aumento da qualidade individual do trabalhador em sua coletividade, e o próprio formato da empregabilidade, nas relações atuais? Essas características só são afirmativas no que tangem à disputa entre os trabalhadores. Essas qualidades são critérios de seleção e de exclusão para um emprego; conseqüentemente, é o segredo das relações sob o formato das competências, que esconde seu lado perverso e, mais grave, transforma os ditames positivos, formalmente, em ditames de submissão, na prática. $O$ controle passa a ser internalizado, a autonomia ocorre no sentido para aumentar o capital, a participação deve levar os trabalhadores a pensarem e a se comportarem como se fossem capitalistas. O processo de subsunção - controle e submetimento - adquire um novo parâmetro. Posiciona o trabalhador sob a lógica do capital e seu fiel defensoriv.

O modelo das competências, sob o ponto de vista menos perverso, requer uma humanização do capital, em nossa opinião, algo impossível de acontecer na reprodução capitalista. Processos de melhorias de condições de vida - parte da 'humanização' - existem fundamentalmente graças à resistência e à luta dos trabalhadores contra o capital e às raízes civilizatórias que há muito já foram invertidas pelo capital. Numa situação mínima de reprodução, os capitalistas necessitam de ter a força de trabalho a ser explorada com o máximo de preparação e com mínimos custos para atingir os seus objetivos. O lado tratado como positivo é cada vez mais restritivo para o conjunto da classe trabalhadora, vide o 
issn: $1808-799 \mathrm{X}$

ano 6 - número 7 - 2008

desemprego, o subemprego, o trabalho escravo, infantil etc. crescente no mundo. Ou seja, o aspecto civilizatório do capital é cada vez mais restritivo e excludente, no sentido de apropriação da civilização pela maioria, não do sistema, obviamente, pois é necessário incluir num sistema exploratório cada vez mais propulsor de miséria, desemprego e guerras. Essa humanização sistêmica proposta ou imaginada é incompatível com a realidade do movimento do capitalismo. O que temos como humanização são fragmentos da mesma, exatamente na contraposição e afastamento do capital. Mesmo sendo parcial, o sentido maior da ressignificação não pode ser de legitimar o capital, ou de simplesmente humanizá-lo, como a pós-modernidade representa-o sutilmente.

Não se pode confundir a necessidade de acumular forças, uma tática de resistência construída, com a das estratégias negadoras da ruptura com o capital e, portanto, assumindo indiretamente a possibilidade da máxima do 'fim da história'. Por outro lado, muitas das perspectivas bem intencionadas dessa resistência tornam-se processos legitimadores da manutenção do capital. Ou, ainda, algumas bandeiras de luta dos trabalhadores são tomadas pela burguesia para frear as conseqüências danosas aos seus interesses. 'Vão-se os anéis...' Os conceitos de participação, autonomia, no modelo de competências, podem ser caracterizados como elementos tomados pela burguesia para superar sua crise e submergir o trabalhador em seus interesses. Agora, quando configurados no conjunto de noções ou do modelo de competências, assumem significados determinados pelo capital, mais do que isso, de forma intrínseca compõem a formação fetichizada da força de trabalho.

Uma das premissas levantadas pelos críticos ao capital, dentro da lógica da pósmodernidade, do fim do trabalho enquanto categoria central é o reconhecimento das diferenças, das humilhações impetradas pelos dominantes, concluindo de que só existe o espaço de frear e de minimizar os efeitos do capital, cada vez mais internacionalizado, no local, no individual, no particular.

A aceitação da existência de um espaço de lutas dentro do capitalismo é o reconhecimento de uma sociedade em movimento em disputa de contrários. Entretanto, não podemos esquecer que a mesma tem um resultante histórico, que se transforma em condicionamento, que é ser dominada pelo capital. Não é uma disputa com forças em pé de igualdade. O capital, através dos capitalistas e asseclas, tem o controle fundamental. Os trabalhadores assalariados, no processo de sua sobrevivência, reproduzem essa sociedade. No caso, o papel das competências é de fortalecer esse processo reprodutivo, condicionado 
issn: $1808-799 \mathrm{X}$

ano 6 - número 7 - 2008

em favor do modo capitalista de produção atual.

O fato de reconhecermos a disputa não nos pode fazer capitular na fetichização desenvolvida no capital e em suas categorias. Devemos distinguir o que é disputável, no sentido de acumular forças para a luta de sua extinção e o que é trabalhar para a legitimação da lógica burguesa, sem efetivar a construção da rupturav ${ }^{v}$. No nosso entendimento, a efetivação da disputa, no campo ideológico, é a própria denúncia da parcialidade e da instrumentalidade, apontando essa prática como 'enfeitiçada' e que, concretamente, reforça o sistema capitalista e suas várias ações junto aos trabalhadores, inclusive o fetichismo das competências que compõe a totalidade capitalista.

É fundamental entender que o modelo de competências existe, na prática, mas que não é emancipatório, pois está muito bem definido e praticado, por parte dos capitalistas, em suas finalidades históricas de reprodução do processo de exploração. São armas de combate para os próprios trabalhadores competirem entre si e não contra os capitalistas. É a preparação dos gladiadores para sua sobrevivência na arena do trabalho. Trata-se de um grande fetiche, que transforma a necessidade do capital como necessidade da coletividade, em especial, como formadora da força de trabalho. É importante frisar que o fetiche tem as suas bases nas práticas sociais existentes. Não pode ser considerado somente como um problema que se apresenta no campo ideológico, ele é fundamentalmente prático.

Como exemplo podemos apontar a categoria capitalismo. Na lógica marxista, essa categorização da realidade, no que tange a possibilidade de ser colocada em favor da classe trabalhadora, não está em disputa ${ }^{\mathrm{vi}}$. O capital, em sua forma organizativa, na prática, não tem como ser favorável aos trabalhadores, em sua totalidade, apesar de existirem elementos conquistados pelos trabalhadores, devido à própria dinâmica da luta de classes. O capitalismo é uma forma dominante de organização da sociedade. Dentro da lógica da emancipação não há como construi-lo e, portanto, desejar de forma conseqüente um capitalismo favorável aos trabalhadores. No nosso entendimento, a categoria das competências está no mesmo campo prático e teórico.

Diante deste quadro de referências, reafirmamos a impossibilidade de uma formação da força de trabalho mercantilizada, das competências dos trabalhadores estar sob a lógica dos trabalhadores. Afinal, não seria uma mudança conceitual mudaria as práticas e interesses que Ihes correspondem na atualidade. Por si só, é impossível, a não ser que seja uma mágica semântica, um 'capitalismo social', ou 'socialista', no caso, uma 'competência social' ou 
issn: $1808-799 \mathrm{X}$

ano 6 - número 7 - 2008

'socialista'. A expressão 'capitalismo' refere-se a uma prática social cristalizada nas relações humanas de exploração, com seus fundamentos estabelecidos historicamente. No mesmo entendimento está a categoria de competência, uma prática social cristalizada em favor dos capitalistas. Uma prática de luta, de competição, para fragmentar os próprios trabalhadores.

\section{A impossibilidade de ressignificar o capitalismo para os trabalhadores.}

No nosso entendimento, ressignificar o modelo de competências pressuporia à própria ressignificação do capitalismo. Dentro do modelo político-econômico do neoliberalismo, recolocar teoricamente o modelo das competências tem um sentido legitimador das políticas do mesmo. O que ocorre, na verdade, é um tipo de ressignificação do projeto dos trabalhadores feita na prática pelo movimento sindical. De que forma? Quando a CUT (Central Única dos Trabalhadores) abandona sua radicalidade contra o capital e passa a apontar a cidadania como o seu eixo central, uma ressignificação em favor da legitimação da ordem vigente, e não um patamar para o seu questionamento e enfrentamento real.

Amaral (2005) analisa as modificações concretas que ocorreram no movimento sindical brasileiro, tanto em suas orientações como em suas práticas. Considera que o eixo organizativo, com um alicerce classista, combativo e revolucionário, dá passagem à concepção que privilegia a participação propositiva no sistema, a defesa da cidadania e a realização de políticas públicas. Evidentemente que as visões reformadoras 'humanistas' do capital vão crescer com uma conjuntura ideológica favorável ao capital, portanto, adversa à classe trabalhadora.

Os documentos da CUT, relacionados, principalmente, à política industrial e à política educacional, nos parecem ser ilustrativos de uma mudança de posição da Central, a qual passa a incorporar as mudanças no campo da economia como elementos inexoráveis à conjuntura brasileira e a propor conteúdos, posturas e instrumentos conciliatórios que apostam em ganhos para os trabalhadores, na perspectiva de reversão das desigualdades sociais, e em uma agenda propositiva que admite concepções liberalizantes na condução de políticas setoriais, a exemplo da necessidade de redefinição da relação do Estado com o mercado (Amaral, 2005, p.27).

Kuenzer conjuga essa nova forma de fazer sindicalismo 'radical' em duas pilastras de conteúdos: a ética e a cidadania. Estas são os alicerces para discutir política e sociedade: 
issn: $1808-799 X$

ano 6 - número 7 - 2008

das relações sociais, privilegiando-se conteúdos demandados pelo exercício da ética e da cidadania, os quais se situam nos terrenos da economia, da política, da história, da filosofia, da ética, e assim por diante (Kuenzer, 2004, p.16).

Este é o patamar da nova perspectiva da 'praxis revolucionária', que tem preocupações com a qualidade de vida, com a participação diante dos progressos tecnológicos e das novas formas de organização. Tudo isto num tom de conciliação entre as classes. Finalmente, como conclusão, a autora afirma: "Resta saber quantas empresas se disporão a esta tarefa, posto que esta opção trará impactos também sobre a democratização do produto do trabalho, em contraposição à lógica que rege o capitalismo" (Kuenzer, 2004, p.17). O processo de conciliação depende efetivamente da boa vontade do empresariado... ${ }^{\text {vi }}$

Por outro lado, Moraes enfatiza a importância da prática além da nomenclatura: "De qualquer maneira, independente da terminologia a ser utilizada - competências ou qualificação - o que importa politicamente é atribuir-lhe um conteúdo que responda às necessidades/interesses dos trabalhadores" (2002, p.15).

Isto é parcialmente correto, pois uma boa definição teórica, ou seja, uma reflexão mais aproximada da realidade pode delinear melhor os rumos em que a nossa prática - e a própria teoria enquanto aproximação da realidade e de fundamentos para sua transformação - deva tomar. Caso contrário, não existiria necessidade de estudarmos teoricamente a realidade.

No que diz respeito a respeito das competências, carregam consigo seu princípio básico, que é o aumento da produtividade a partir da concorrência entre os trabalhadores. $A$ anterior lógica da qualificação também sempre esteve no âmbito do desenvolvimento do capitalismo. Com uma diferença básica: a primeira corresponde, à época do estado de BemEstar Social, ao fordismo, à lógica keynesiana, a segunda corresponde às políticas neoliberais, ao enfraquecimento do Estado provedor, à acumulação flexível, à fragilização do movimento sindical, etc. Entretanto, ambas respondem pela caracterização capitalista da força de trabalho como mercadoria, só que no modelo de competências com uma maior radicalidade capitalista.

\section{O fim da URSS, a crise do socialismo e a questão do subjetivismo.}

$\mathrm{Na}$ crise dos países do bloco socialista europeu de então, na nossa análise não foram somente problemas endógenos que favoreceram sua derrocada. O capital, além de financiar a guerra fria, avançou, a partir de uma intervenção vitoriosa em sua concepção neoliberal para dentro dos países do leste europeu, a União Soviética, alguns países africanos e o leste 
issn: $1808-799 X$

ano 6 - número 7 - 2008

asiático, em especial a China, que se organizavam sob a bandeira do socialismoviii. Na Europa, realizou-se um processo de transformação política, implementando modificações profundas na ordem desses Estados, que, aprofundou-se com a derrocada do falido bloco hegemonizado pela União Soviética, trazendo como conseqüência um processo fortíssimo de crise da perspectiva da construção de projeto de sociedade socialista para a classe trabalhadora no mundo inteiro. Com a queda do bloco soviético, diminui a influência teórica da concepção marxista. Em geral, no mundo todo, abriram-se espaços para teorias se não resolutamente favoráveis ao capital, mas com uma subjugação ao vencedor do momento: 'Ao vencedor as batatas...'

Os teóricos da pós-modernidade representam muito bem esse momento de resposta à crise. Poderíamos apontar que essa crise do capital teve como efeito a utilização de uma rede fina, por parte do capital, trazendo para si os mais diversos intelectuais em uma profunda crise prática e teórica. Com isso, volta com força a perspectiva teórica da burguesia e junto com ela suas expressões, como o ecletismo, o pragmatismo, o pós-modernismo, o neopositivismo, entre outras.

É a volta ao subjetivismo, da não objetivação da verdade, da falta de perspectiva da ruptura com a sociedade vigente, no que ela tem de essencial, que é a exploração do planeta e da maioria dos sujeitos sociais. Essa situação é vivida em seus inúmeros formatos, colocando na rota do empobrecimento a maioria, em benefício de uma camada que vive desse trabalho explorado. Dentro dessa confusão prático-teórica, existem aqueles bem intencionados que estão em defesa das competências de forma crítica, de condenação ao projeto político neoliberal. Vejamos como Deluiz vai apresentar a positividade dessa lógica de forma contraditória:

A matriz construtivista apresenta, assim, pontos de positividade ao atribuir importância não só à constituição de competências voltadas para o mercado, mas direcionadas aos objetivos e potencialidades do trabalhador; ao considerar o trabalho em suas relações contextuais e buscar a construção de competências coletivas; ao possibilitar a transposição das competências investigadas no processo de trabalho mediada por uma concepção pedagógica. Entretanto, para os construtivistas, a construção do conhecimento é considerada como um processo individual, subjetivo, de desenvolvimento de estruturas cognitivas, em uma perspectiva naturalista da aprendizagem, sem enfatizar o papel do contexto social para além da esfera do trabalho na aprendizagem dos sujeitos. A concepção de autonomia fica, desta forma, limitada à sua dimensão individual, focada no mundo do trabalho. Apresenta, assim, uma concepção mais 
issn: $1808-799 X$

ano 6 - número 7 - 2008

ampliada de formação, mas minimiza a sua dimensão sóciopolítica (Deluiz, 2001, p.10 - Grifos nossos).

A primazia pelo lado subjetivo demonstra seu afastamento epistemológico do materialismo dialético. É o limbo do relativismo. Nessa relatividade estão posicionadas as competências, sob a ótica de uma burguesia humanista. É evidente que todas as concepções têm aproximações importantes com a realidade, umas deixando-as claramente reveladas, outras propondo a manutenção da submissão dos trabalhadores. O problema, ao nosso ver, está na utilização de um método fragmentado, no qual o objeto é analisado, tanto na interpretação correta da realidade, reforçando-a, quanto nas propostas idealistas para a realidade, deixando-as impraticáveis. É um problema dado pelo seu idealismo, defendido a partir da lógica da pós-modernidade, que contribui para a legitimação de uma situação social típica das práticas capitalistas individualizantes. Eis um ponto central de sua inviabilidade.

Os pontos positivos são colocados também pelo capital, quando propõe uma maior escolarização. Não se pode analisar um conjunto por suas particularidades, de forma separada. O movimento do capital, a definição deste, bem como a resposta subjetivista, como nos afirma Duarte (2003), são insuficientes e contradizem uma visão de emancipação da classe trabalhadora. Ramos vai apontar o caráter ahistórico da lógica subjetivadora da realidade.

Concluímos então que, de acordo com essa perspectiva, o conhecimento não resultaria de um esforço de compreensão da realidade objetiva, mas das percepções e concepções subjetivas que os indivíduos extraem do mundo experiencial. A validade do conhecimento assim compreendido é julgada por sua viabilidade ou por sua utilidade exclusivamente neste âmbito e, muito além de ser considerado histórico, é tido como contingente. Ou seja, não existiria qualquer critério de objetividade, de totalidade ou de universalidade para se julgar se um conhecimento, ou um modelo representacional, é válido, viável ou útil. (Ramos, 2003, p.101)

A epistemologia apresentada carece de um fundamento histórico dentro do movimento dos interesses contrários explícitos. As relações sociais de produção são fundantes para a definição da forma como se expressa a própria compreensão da realidade, ou seja, não se encontra deslocada da prática histórica. A formação da coletividade, neste modelo, assume um caráter individualizante, de expressão fragmentada dos trabalhadores. Contraditoriamente, por mais que se coloque que a formação seja um ato individual, o processo de conhecimento e de socialização só pode ocorrer na coletividade, mas no caso, uma coletividade fragmentada, em que os sujeitos para sobreviver devem competir entre si. ${ }^{i x}$ 
issn: $1808-799 \mathrm{X}$

ano 6 - número 7 - 2008

Não é ocasional que uma das suas caracterizações seja o enfraquecimento da coletividade, entendendo-a como organização que contesta a ordem burguesa. Além do enfraquecimento das lutas, a formação fica sendo individualizada, não no necessário conjunto do processo produtivo, mas no sentido da luta dos trabalhadores, na remuneração, com carreiras enfraquecidas, no tratamento dado pelo capital em relação aos trabalhadores. Somado a isto, há ainda o reforço das teorias pseudolibertárias, ressaltando a individualidade, a subjetividade, sem conexão com a objetividade, acentuando seus interesses de fragmentação dos trabalhadores e das suas organizações. No caso, o movimento de unidade é feito pelo capital, com a manutenção de seu controle. Parece ambígua, pois, de um lado, favorece a fragmentação, e, de outro, a unidade. No entanto, é o capital que vai organizá-la, em seu proveito. Para tal, a competência tem um papel de destaque. O capital expulsa as tentativas dos trabalhadores de trazerem a autonomia e a unidade para o seu âmbito, pois é de um antagonismo real. Para nós, trazer as competências para o terreno dos trabalhadores é, fundamentalmente, negar a exploração, portanto, negar o modelo de competências.

O modelo das competências remete, assim, às características individuais dos trabalhadores. O modelo das qualificações ancorado na negociação coletiva cedeu lugar à gestão individualizada das relações de trabalho. A relação de coletivos (a empresa) com indivíduos tende a enfraquecer as ações coletivas no campo do trabalho e a despolitizar a ação política sindical (Deluiz, 2001, p.3).

Características individualizantes levam a crer que há uma característica dissociada das relações sociais. Ou seja, a responsabilidade, o saber ser, são tratados como problemas individuais e não de dominação de uma classe sobre a outra. É a fragmentação do mundo incorporado, negando a totalidade e as marcas da mesma, como a exploração, a alienação e o fetiche. Essa característica individualizante é contraditoriamente e essencialmente coletiva, sob a lógica fragmentada do capital, e válida para todos os trabalhadores, com as diferentes exigências, conforme a divisão do trabalho, internacional, sexual, regional etc. para os trabalhadores da ativa e parte do exército de reserva.

\section{O caráter polissêmico das competências}

Outro argumento, também muito utilizado, diz respeito à caracterização polissêmica do vernáculo 'competência'.

Esta polissemia se origina das diferentes visões teóricas que estão ancoradas em matrizes epistemológicas diversas e que expressam interesses, expectativas e aspirações dos diferentes sujeitos coletivos, que possuem 
issn: $1808-799 X$

ano 6 - número 7 - 2008

propostas e estratégias sociais diferenciadas e buscam a hegemonia de seus projetos políticos (Deluiz, 2001, p.11).

Caracterizar competência como polissêmica seria dar um significado conforme o seu contexto - o que não é o caso da competência aplicada na formação da força de trabalho ${ }^{x}$-, pois não resolve o problema prático e teórico de, simplesmente, achar que um conceito possa servir aos seus opostos, sem realizar um movimento concreto dialético. Lembremo-nos de que o movimento de seu contraditório é um movimento de aproximação à própria realidade. $O$ movimento dialético obedece à imposição da construção do próprio objeto, o que não é algo aleatório, nem pode ser a sua construção uma ação arbitrária, ou somente responder a um desejo sem uma base material de sua significação. Ou seja, as competências, na prática, teriam que ter em seu seio, no seu alicerce, o não atendimento dos interesses das empresas, dos capitalistas, mais precisamente. Não é por acaso que todas as correntes que utilizam as competências como conceito, noção ou categoria, abordam a necessidade do consenso dos trabalhadores com os empresários em sua definição prática e teórica.

Num estudo de Ramos sobre a possibilidade de uma pedagogia das competências, a autora vai aprofundar os termos epistemológicos que fundamentam a lógica das competências em comparação a uma perspectiva emancipatória dos trabalhadores. No caso, Ramos (2001), baseada em estudos de Duarte (2003), defensora da ressignificação vai rever sua posição num texto publicado em 2003.

Portanto, para ser possível uma pedagogia das competências contrahegemônica teríamos de suprimir exatamente o termo que nos impede de admitir os princípios anteriores: competências. Voltamos, então, à questão central da formação humana sob o modo de produção capitalista: a necessidade de construção de uma pedagogia contra-hegemônica, que seja ativa e criadora, construída com base em uma profunda e orgânica ligação entre ela e o específico dinamismo social objetivo que nela se identifica. Concluímos, então, que a pedagogia contra-hegemônica pode ser construída na perspectiva histórico-crítica, resgatando o trabalho como o concreto princípio educativo.( Ramos, 2003, p.111).

A modificação da posição de Ramos, a partir de estudos realizados com Duarte, tendo como eixo uma discussão epistemológica, coloca no seu devido lugar o antagonismo de classes que também em suas variadas expressões, no caso, na dita ressignificação das competências. Justamente porque o significado fundante é alicerçado na perspectiva capitalista. Uma contraposição clara do antagonismo de classe, prática e teoricamente, só terá sentido calcada em pilares opostos. É aí que se define concretamente a dialética histórica 
issn: $1808-799 X$

ano 6 - número 7 - 2008

materialista. Ramos, então, aponta o trabalho como uma perspectiva histórica crítica, afastando-se da ressignificação eclética.

A necessidade da contraposição de projetos de classes sociais antagônicas aponta em caracterizar esse antagonismo, e não diluí-lo como uma diferença qualquer, como se pudéssemos uma categoria hodierna de formação da classe trabalhadora, adaptar, resgatar elementos sem levar em consideração seu sentido fundamental, esvaziando o seu sentido fundante que é localização alienada do trabalho. A palavra competência pode ser utilizada de diversas formas, só que o modelo de competências, por mais que tenha matizes teóricas e diferentes interpretações, no que tange à formação para o trabalho, é oriundo da política hodierna do capital para adequar sua força de trabalho à resposta de sua crise. De fato, atuase para contribuir à capitulação, cada vez com mais vigor, levando às iniciativas dos trabalhadores e formando uma classe trabalhadora cada vez mais identificada com o capital: 0 fetiche da competência.

\section{Competências, um fetiche do capital}

Não é sem sentido toda a preocupação burguesa com a formação da classe trabalhadora. Existe toda uma movimentação dos mais diversos setores para inculcar essa grande nova conquista dos tempos atuais: a possibilidade da redenção da pobreza, da exclusão, da exploração, via uma nova e simpática educação.

Os pilares desta nova formação da força de trabalho são alvissareiros para qualquer trabalhador: mais autonomia, mais criatividade, unidade do trabalho consigo mesmo, um trabalho sem o aborrecimento da repetição, cheio de novidades e desafios.

A crise do capital propiciou toda uma mudança no intuito de superar a tendência de diminuição da taxa de lucro do capital, crise essa expressa de inúmeras formas, como a inflação, o crescimento dos custos sociais dos Estados, a perda de direitos conquistados por parte dos trabalhadores, especialmente dos centros mais dinâmicos da economia. Nesse movimento, com uma força prática e ideológica de derrubar as fronteiras para a diminuição do custo das mercadorias, coube à parte da mercadoria especial - a força de trabalho - o seu quinhão.

No intuito de diminuir o custo do capital variável, as mudanças profundas no processo tecnológico e a reorganização interna da produção constituem duas partes do tripé. Faltava a 
issn: $1808-799 X$

ano 6 - número 7 - 2008

terceira: não só baratear os custos dessa mercadoria especial, mas poder dar o salto de qualidade, respondendo aos outros dois 'pés', sem aumentar seu custo. Ou seja, necessitavase de um barateamento da força de trabalho em pleno processo transitório de organização do processo produtivo. A saída era incorporar ao máximo a lógica do 'novo' capital com um mínimo de trabalhadores, mas tendo como bases de seu barateamento, do sujeito coletivo, a tecnologia, as formas organizativas intensivas e a formação de um trabalhador bem preparado, incluindo um enorme exército de reserva.

As modificações de vulto nas tecnologias aplicadas no trabalho servem como base prática do suporte ideológico. Com elas, novas posturas são exigidas dos trabalhadores, situação esta relativizada pelos próprios teóricos do capital, que vão enfatizar o trabalho mais comprometido com a inteligência do capital para enfrentar uma dura concorrência, mais do que o 'manuseio' ancorado nas novas tecnologias.

A denominada 'sociedade da informação' não está voltada diretamente para aqueles que vão trabalhar com máquinas, mas àqueles que vão conseguir aumentar os ganhos do capital, num processo de absorção dos conhecimentos dos trabalhadores. A contradição se revela quando se está diante de exigências de uma força de trabalho mais próxima dos interesses do capital, em tese, negando a sua identidade antagônica. Na prática, significa perder inúmeras conquistas trabalhistas, através do aumento dos processos de precarização. O lado bom da flexibilização, cantado em verso e em prosa, tanto a partir das formas flexíveis de produzir, ou do uso da tecnologia mais sofisticada, tem umbilicalmente ligado a ela o seu outro lado: a flexibilidade dos direitos trabalhistas, ou mais precisamente, a perda de direitos dos trabalhadores. Nisto, não poderíamos deixar de apontar que a maior precarização, sob o manto novo e mais profundo da terceirização, por exemplo, é uma exigência básica para se implementar a sedutora flexibilidade, elemento básico das competências. Não existe o modelo das competências fora dos institutos supra-estruturais atualizados pela nova forma de produzir do capitalismo.

As organizações buscam, através do modelo de competências, introjetar nos trabalhadores valores e práticas típicas dos capitalistas. Evidentemente, sem as mesmas benesses dos mesmos, cindidos pela propriedade dos meios de produção de uns, e, de outros, a propriedade apenas de sua força de trabalho.

Além da flexibilidade presente no modelo das competências, ressalta-se a autonomia. Louvados pelo mercado são considerados como processos de liberalização dos entraves do 
issn: $1808-799 \mathrm{X}$

\section{ano 6 - número 7 - 2008}

modo de organização da produção taylorista, estes, rotineiros e embrutecedores. Essa autonomia e essa liberdade criativa, na verdade, caminham somente na direção do aumento da extração da mais-valia, de um processo de subsunção real, sem descartar o aumento da jornada de trabalho, controlando, portanto, ao mesmo tempo, contraditoriamente, por novos meios sutis, esses trabalhadores, em tese liberados em sua criatividade e iniciativa, mas presos numa nova e férrea lógica de controle muito mais profunda. É evidente que esse modelo não comporta muros grandes e visíveis, mas, sim, cercas de campos magnéticos, invisíveis aos olhos 'enfeitiçados'.

A autonomia está diretamente ligada aos ganhos do capital. Ou seja, não existe uma autonomia sem adjetivação: ela é a autonomia para o capital, ou autonomia das competências para o capital. É o novo saber exigido, o saber ser, ser um trabalhador feliz com a sua condição de 'pequeno-capitalista'. O interessante é que existem inúmeros mecanismos práticos, como a terceirização, ou a participação em ações das próprias empresas em que o trabalhador é explorado, além dos recursos do discurso ideológico, utilizado por vários meios de comunicação, muitos deles com uma verdadeira força material, em defesa das competências. O exemplo desta contradição apresenta-se quando uma empresa aumenta os ganhos para os seus acionistas, justamente no momento da divulgação ou realização de um projeto de reengenharia ou similar, com demissões, terceirizações, etc.

A perversidade do controle não está mais no chicote às costas. Está escondida no exército de reserva, na autonomia, na criatividade, nos novos processos de subsunção da vida social. Todos esses paradigmas do saber ser, junto com o saber fazer, contribuem para 0 aumento da exploração dos assalariados, por parte do capital. Os trabalhadores são seus próprios capatazes. Esse controle não é só internalizado abstratamente. Os mecanismos de certificação são exemplos claros. Da certificação das competências de cada trabalhador, retirando as referências de diploma, de tempo de serviço e outras que os trabalhadores tinham no modelo anterior, indo até para um processo complexo de avaliação e, obviamente, de controle. Este ponto causa arrepios nos defensores das competências, pois 'nem sempre' as empresas 'pagam' a sua parte, um problema a ser corrigido, segundo os mesmos.

O processo de controle transformou-se num processo sistêmico, uma vez que a empresa continua com seus fiscais e, que, os gerentes, diretores, capitalistas ainda mandam e 'desmandam', além do próprio controle internalizado nos trabalhadores, que se chicoteiam para serem 'o melhor', para terem o emprego e que assumem a 'mea culpa' na demissão. Quando 
issn: $1808-799 \mathrm{X}$

\section{ano 6 - número 7 - 2008}

não atingem o que deles era esperado estarão na 'rua da amargura'. Mas não podemos esquecer que o controle é oriundo do próprio processo produtivo, da regulação dos meandros da produção e reprodução do capital, inclusive da subjetividade da classe trabalhadora.

Assim, as mais modernas formas internacionais de controle da produção, efetivada e reconhecida mundialmente como a ISO (International Organization for Standardization), em que estão prescritas desde as inocentes medidas em que o papel A4 deve possuir, passando pelas formas de citação determinadas pela ABNT (Associação Brasileira de Normas Técnicas), até os mais complexos procedimentos na área gestacional, de segurança, ambiental, da indústria química, de diversos processos produtivos. São tão detalhados os movimentos controláveis que não caberiam na nossa imaginação configurando-se como um controle sistêmico do capital, por serem compatíveis, ou melhor, intrínsecos à relação entre as competências e o domínio da força de trabalho. O grande sentido deste processo é a glorificação das mercadorias. Para tal, o controle ocorre nos mínimos detalhes, desde o planejamento, passando pelas operações, até as ações 'invisíveis' de gestão. Tudo está sob controle, ou, pelo menos, pretende-se estar.

Firmamos que o modelo das competências, ou mesmo sua noção, está vinculada à racionalidade de desenvolver a força de trabalho enquanto uma mercadoria, sujeita às suas caracterizações. O fetiche, no caso, ocorre quando a força de trabalho é requerida no formato das competências, reforçando seu caráter de mercadoria. Mas, mais do que isso, ela tem as características fundamentais do fetiche: a sua perda de referência nas relações sociais produtivas. As características das competências para os trabalhadores estão fundadas na imagem e semelhança de sua classe antagônica, com os fundamentos originados na gerência capitalista, cabendo até nos mais exóticos exemplos, porque é a resposta para uma lógica hegemônica de organização da produção, a lógica do capital.

O fetiche coisifica as relações ou as naturaliza, exatamente pela perda por parte do trabalhador do controle da produção e do seu produto. Ele não é só uma abstração. Parte das relações concretas existentes, no caso, de subsunção real do capital aos trabalhadores. Portanto, é incompatível a versão 'light' do modelo das competências dentro das formas vigentes de exploração da força de trabalho. Também é impossível 'ressignificar o significado' na lógica dos trabalhadores, se não ocorrer uma ruptura com a forma mercadoria da força de trabalho. Esta é uma questão central do fetiche: tratar a força de trabalho na perspectiva do mercado, ou melhor, como uma mercadoria, sujeita a todas as leis pertinentes à mesma. 
issn: $1808-799 X$

ano 6 - número 7 - 2008

Existem correntes ligadas a movimentos sociais que se resignam, na teoria e na prática, à força das regras impostas pelo mercado. No máximo, é desejada, como finalidade mínima possível, para os trabalhadores, uma melhoria de suas condições de vida, dentro da exploração capitalista. No caso, a ressignificação é um contra-senso de quem quer romper com o sistema capitalista. Ela representa a subjugação da teoria crítica materialista dialética à impossibilidade da ruptura e construção de uma sociedade que não coisifique os trabalhadores. Ela joga somente para uma menor coisificação, ou numa coisificação factual, ou para a redenção de parte da classe dos trabalhadores, portanto, impossível, em sua praticidade.

Assim, pretendemos defender a tese de que as competências se constituem parte da ação do capital, no tratamento da força do trabalho enquanto mercadoria especial. E, por ser especial, passa por um processo de controle mais sofisticado pelo 'novo' capital. Uma das principais expressões dessa nova formatação é, exatamente, a fetichização das competências. A competência é uma representação de uma formação maravilhosa para os trabalhadores, numa contradição antagônica com a verdadeira intencionalidade e prática do capital. Ela representa a mistificação da ordem e a sua naturalização. Modelos de competências, modelos exemplares de fetiche da mercadoria força de trabalho.

\section{Referências Bibliográficas}

AMARAL, Ângela Santana do. 2005. Qualificação dos Trabalhadores e estratégia de hegemonia: o embate de projetos classistas. Tese de doutorado, Rio de Janeiro: Universidade Federal do Rio de Janeiro.

DELORS, Jacques. 2006. Educação: um tesouro a descobrir. 10ª ed. São Paulo/ Brasília (D.F.) ; MEC/ UNESCO e Cortez.

DELUIZ, Neize. 2001. O modelo das competências profissionais no mundo do trabalho e na educação: implicações para o currículo. Boletim Técnico do SENAC. Rio de Janeiro, 27 (3): Setembro/Dezembro.

DUARTE, Newton. 2003. Sociedade do conhecimento ou sociedade das ilusões? Campinas: Polêmicas do nosso tempo, Autores Associados. 
issn: $1808-799 X$

ano 6 - número 7 - 2008

FRIGOTTO, Gaudêncio. 1996. Educação e a Crise do Capitalismo Real. São Paulo: Editora Cortez.

KUENZER, Acácia. 2002. Educação, linguagens e tecnologias: as mudanças no mundo do trabalho e as relações entre o conhecimento e método. In: CANDAU, Vera. Cultura, linguagem e subjetividade no ensinar e aprender. Rio de Janeiro: DP \& A Editora.

2002a. A Pedagogia da Fábrica: as relações de produção e a educação do trabalhador. São Paulo: Cortez.

2004. Competência como Práxis: os dilemas da relação entre Teoria e Prática na Educação dos Trabalhadores. Boletim Técnico do SENAC. Rio de Janeiro, 30(3): set./dez.

MARX, Karl. 1985. Miseria de la Filosofía. Moscu: Editorial Progreso.

1989. O Capital: Crítica da Economia Política. Livro 1. Vol I. 13ª ed., rio de Janeiro: Bertrand Brasil.

MORAES, Carmen. 2002. Educação, trabalho e formação profissional. In: PRADO, Maria Ligia \& VIDAL, Diana (orgs). A Margem dos 500 Anos: reflexões Irreverentes. São Paulo: EDUSP.

RAMOS, Marise. 2001. A pedagogia das competências: autonomia ou adaptação? São Paulo: Cortez.

2003. É possível uma pedagogia das competências contra hegemônica? Relações entre pedagogia das competências, construtivismo e neopragmatismo, FIOCRUZ, Trabalho, Educação e Saúde, 1(1): 93-114.

TUMOLO, Paulo Sérgio. 2000. Da subsunção formal do trabalho à subsunção real da vida social ao capital: apontamentos de interpretação do capitalismo contemporâneo. XXIII Reunião da ANPED. Caxambu: Associação Nacional de Pós-Graduação e Pesquisa em Educação. 
issn: $1808-799 X$

ano 6 - número 7 - 2008

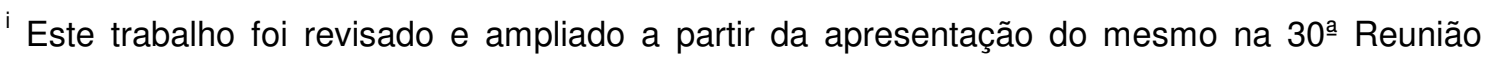
Anual da ANPEd, no GT Trabalho e Educação, em 2007.

ii Bom ressaltar que no seu livro "A Pedagogia da Fábrica", uma pesquisa realizada no início dos anos de 1980, Kuenzer tinha uma posição muito clara em relação ao processo de formação que o capital propunha para os trabalhadores: "Se são as relações sociais e técnicas de produção que educam o trabalhador e se, no modo de produção capitalista, estas relações se caracterizam pela divisão e heterogestão, encontram-se aí, no processo de trabalho assim constituído, o fundamento da pedagogia do trabalho" (KUENZER, 2002a, p.12).

iii Como já havíamos citado, em seu livro 'Pedagogia da Fábrica', Kuenzer propõe: "A utopia, portanto, está na autogestão, compreendida como o controle da produção por todos os homens, com o estabelecimento da hegemonia do trabalho sobre o capital' (KUENZER, 2002a, p. 56). Como podemos ver, essa postura pressupõe o fim da subsunção do trabalho pelo capital, no controle da produção pelos trabalhadores, situação impossível de ser defendida em qualquer molde do capitalismo.

iv A competência é a expressão fetichizada dessa nova subsunção real da vida, de acordo com Tumolo (2000).

${ }^{v}$ Essa perspectiva histórica lembra-nos do reformismo histórico, com a lógica internista de que por dentro do capitalismo poderia se construir uma nova sociedade. Com uma diferença, ele apontava para uma sociedade claramente socialista.

vi Aprofundando a questão poderíamos dizer que no capitalismo os trabalhadores realizam a disputa de classes, só que a disputa dentro do capitalismo, limitado às reformas, não é exatamente uma disputa classista de cunho revolucionário.

vii Os primeiros socialistas, chamados de utópicos, aportavam claramente em defesa do fim da propriedade privada dos meios de produção. No entanto, a estratégia fundamental destes pioneiros, era a abolição da propriedade via convencimento da burguesia, sem a participação 'desordeira' do proletariado. Para tal, apontavam para a necessidade de construir vilas comunitárias como demonstração para a sociedade do novo modo de organizar-se socialmente, em contraposição ao enfrentamento entre as classes.

o Outros autores descrevem que não existia socialismo, e sim, capitalismo de Estado. Em princípio, achamos que a estrutura organizacional apontava para o um socialismo burocratizado, tornado-se uma degeneração do Estado proletário, mas não trataremos do assunto neste trabalho.

${ }^{i x}$ Evidente que a expressão e o assumir os conhecimentos existentes é de forma individual (Duarte, 2003).

${ }^{x}$ No nosso entendimento existe, sim, uma diferenciação, mas não no campo do capital como formador de sua força de trabalho, mas, no que tange à aplicabilidade da palavra em questões no âmbito do direito. Ela estava submetida somente a setores que bem exercem sua atividade. No modelo atual, ela açambarca o conjunto da classe trabalhadora, no contexto das políticas neoliberais enquanto resposta à crise do capital.

Prof. Dr. Daniel Alvares Rodrigues - Professor Adjunto do Departamento de Fundamentos Sócio-Filosóficos da Educação - Centro de Educação - Universidade Federal de Pernambuco

Área de Pesquisa: Trabalho e Educação. 